\title{
TORNAR-SE EMPREENDEDOR OU PERMANECER EM UMA GRANDE EMPRESA: SONHO OU ESTABILIDADE?
}

DOI: $10.14211 / 41175$

Recebido em: 30/08/2014. Aprovado em: 29/09/2014.

\author{
Sheila Schlickman Baccin - Universidade do Vale do Itajaí ${ }^{1}$ \\ Christiane Mendes Drozdek Pereira - Universidade do Vale do Itajaí ${ }^{2}$ \\ Sidnei Vieira Marinho - Universidade do Vale do Itajai ${ }^{3}$ \\ Anete Alberton - Universidade do Vale do Itajaít
}

Resumo: O presente trabalho trata de um caso real que visa apresentar através de um dilema pessoal a trajetória de Gabriel frente à necessidade de seguir seu sonho ou permanecer na SinkSul onde ao longo de 14 anos desenvolveu sua carreira adquirindo estabilidade financeira. Gabriel vem se desdobrando entre os trabalhos na SinkSul e seu empreendimento, comprometendo sua vida familiar e pessoal. $O$ caso se destina a estudantes de graduação em Administração, focado na disciplina de empreendedorismo. $O$ aspecto de ensino-aprendizagem parte de alguns conceitos sobre empreendedorismo trazendo os diferenciais dos empreendedores, que motivados pela paixão, deixam sua marca através de seu papel em sociedade, sendo admirados e seguidos por outros empreendedores. O caso pode oferecer situações para orientar os leitores em suas escolhas profissionais. Os alunos devem refletir e abordar conceitos de empreendedorismo, importância do plano de negócios e características empreendedoras de Gabriel, criando discussão e o encaminhamento para a solução do caso.

Palavras-chave: Empreendedorismo, plano de negócios, características empreendedoras, perfil empreendedor.

\section{BECOMING AN ENTREPRENEUR OR STAYING IN A LARGE COMPANY: DREAM OR STABILITY?}

Abstract: This case is about a real situation that seeks to reveal, through Gabriel's personal dilemma, the necessity to follow his dreams or to stay in SinkSul Company where over 14 years he already has developed his career acquiring financial stability. Gabriel has been dividedbetween work at SinkSul and his business, affecting his family and his personal life as well. The case is intended to business administration students, focused on the discipline of entrepreneurship. The aspect of teaching and learning starts with some concepts of entrepreneurship, highlighting entrepreneurs' differences, who motivated by passion, make their mark in society through their role, being admired and followed by other entrepreneurs . The case may offer opportunities to guide readers in their career choices. Students should

\footnotetext{
${ }^{1}$ E.mail: sheila@ampernet.com.br - Endereço: Rua Uruguai, 485 - Centro, Itajaí, SC, CEP: $88302-$ 901.

2 E.mail: christiane.pereira2006@gmail.com

${ }^{3}$ E.mail: sidnei@univali.br

${ }^{4}$ E.mail: anete@univali.br
}

BACCIN, S. S.; PEREIRA, C. M. D.; MARINHO, S. V.; ALBERTON, A. Empreender ou permanecer em uma grande empresa: sonho ou estabilidade? Revista de

Empreendedorismo e Gestão de Pequenas Empresas, v. 4, n. 1, 2015. 
reflect and approach the concepts of entrepreneurship, the importance of business and entrepreneurial characteristics of Gabriel's plans, creating discussion and referral to the solution of the case.

Keywords: Entrepreneurship, business plan, entrepreneurial characteristics, entrepreneur profile.

\section{Introdução}

As pessoas buscam traçar objetivos para suas vidas pessoal e profissional, desenvolvendo carreira em uma empresa ou muitas vezes abrindo seu próprio negócio. Algumas têm a oportunidade de experimentar estes dois caminhos e viver intensamente cada um deles.

Gabriel é um homem jovem que desenvolveu uma excelente carreira na área de desenvolvimento de projetos em uma grande organização metalúrgica. Sempre muito dedicado, aproveitou todas as oportunidades que teve, fazendo viagens pelo Brasil e também para o exterior. As oportunidades vividas no ambiente empresarial Ihe mostraram algumas inquietações, trazendo à tona seu sonho de menino.

Há três anos abriu sua própria empresa na área de usinagem de metais, pois percebeu as necessidades do mercado em que atuava profissionalmente, abrindo assim, novos horizontes a serem explorados.

Nesses três anos, Gabriel desdobrou-se entre seu empreendimento e o cargo na SinkSul. O primeiro, por estar em fase inicial, precisa de muitas horas de dedicação e empenho para que se consiga superar os obstáculos. O cargo na SinkSul também precisa de dedicação, pois foi onde alcançou a estabilidade em sua carreira. Contudo, sua família já está sentindo sua falta e cobrando mais sua presença.

Durante esta longa jornada atuando como profissional e empreendedor, percebeu através do cansaço e da distância de sua família o quanto é importante sua tomada de decisão. Porém, conta com fatores que podem ser críticos para sua vida pessoal e profissional.

As escolhas feitas por Daniel podem definir um novo futuro que trará reflexos nos diversos campos de sua vida. Diante desta indecisão, Gabriel dever tornar-se estável ou empreendedor? Deve vender seu sonho e continuar sua carreira ou enfrentar os desafios de um novo empreendimento? 


\section{Os primeiros caminhos do empreendedor}

Gabriel sempre se mostrou muito curioso e inovador, pois quando criança, seus pais contam que em uma data comemorativa ganhou de presente um caminhão de madeira e a primeira coisa que ele fez foi pegar um martelo e desmontar todo o brinquedo para saber como era feito, tentando montar novamente.

Desde pequeno Gabriel brincava e corria atrás de seu pai na fábrica de móveis da família. Quando tinha por volta de 7 anos, um senhor que trabalhava entalhando madeira veio na fábrica pedir pedaços de madeira para um trabalho que realizava com crianças carentes. Na ocasião seu pai pediu para que Gabriel pudesse participar do projeto para aprender a entalhar. Gabriel se dedicou muito a esse novo projeto, participando não somente do curso, mas também indo várias vezes na casa do professor para aprender o ofício. "Lembro que as esculturas eram feitas em madeira leve, fáceis de cortar, com desenhos, paisagens, animais e figuras católicas. A minha falta de força para cortar a madeira era grande, mas não impedia que os cortes fossem precisos desenvolvendo cada vez mais as habilidades no manuseio com as ferramentas, o entendimento das formas geométricas e a busca pelos mínimos detalhes".

Logo começou a desenvolver carrinhos de madeira com restos de material da marcenaria do pai e conseguiu vendê-los em duas lojas da cidade, se dedicando cada vez mais a esse trabalho. Por volta dos 10 anos de idade já entalhava as peças necessárias para a produção de mesas e cadeiras para a fábrica de seu pai, atendendo a produção.

"Lembro muito bem que meu pai ajudou a pesquisar máquinas para a realização do trabalho, no entanto eram máquinas importadas e muito caras, o acesso era difícil e não tínhamos como pagar."

Gabriel cursou Eletromecânica no CEFET (agora UTFPR) em Pato Branco e em meio à busca por oportunidades iniciou seu estágio na empresa SinkSul, que atua na área de metalurgia. Gabriel ficou muito orgulhoso por estar em uma empresa de sua cidade natal. A empresa lhe ofereceu oportunidades de desenvolver sua carreira e atualmente trabalha na área de engenharia, com desenvolvimento de novos produtos e ferramentas. 
"Quando criança, enquanto assistia a corrida de Fórmula 1 com meu pai, ouvi dizer que um mecânico de Fórmula 1 devia ganhar muito bem, viajar muito e desenvolver carros velozes". Durante o tempo do curso de eletromecânica, além do estágio que lhe trouxe experiência na área mecânica, ele também desenvolveu alguns projetos para um professor do curso, o que lhe proporcionou experiência na área de projetos.

Ao concluir seu curso técnico, decidiu abrir seus horizontes e resolveu prestar vestibular para a área de engenharia mecânica, mas ficava fora de sua cidade natal. Após algumas tentativas fracassadas, resolveu voltar para sua cidade e realizar o curso de Administração em uma faculdade local, permanecendo na empresa como projetista de produtos e ferramentas.

Este trabalho Ihe trouxe muita vivência, a empresa cresceu e tornou-se uma das maiores em seu ramo de atuação, consequentemente ele também foi se desenvolvendo, tendo oportunidades de realizar viagens a trabalho no Brasil e no exterior, viajando para a Turquia, China e Argentina, para visitar fornecedores na área de usinagens de ferramentas e participar de feiras de máquinas. Essas experiências foram incrementando ainda mais seu currículo.

O crescimento da empresa exigiu a ampliação de seus conhecimentos e por seu perfil profissional, a empresa realizou investimentos através de cursos de capacitação, participação em feiras e eventos voltados para a área de mecânica.

O talento de Gabriel ia além do trabalho, em 2005 formou-se com menção honrosa, sendo um dos melhores alunos de sua turma e foi convidado para ministrar aulas na faculdade. Ele aceitou o convite, porém começou sua jornada como professor apenas em 2007, quando iniciou seu curso de pós-graduação em Engenharia de Produção na UTFPR, área que sempre gostou de atuar. Assim, buscava conciliar seu trabalho na empresa e as aulas que ministrava.

Durante esta jornada, Gabriel constituiu família e ministrou aulas por dois anos, até que com a chegada de sua filhinha resolveu parar, porque não estava tendo tempo para sua família devido a sua carga de atividades. "Só pensava em ser papai e aproveitar ao máximo aquele momento". 
As oportunidades de Gabriel na SinkSul foram muito importantes para seu crescimento profissional, sendo reconhecido por suas ideias inovadoras e por sua característica marcante: a persistência nos projetos que liderava.

\section{A história e sonho de Gabriel}

Com 14 anos de trabalho na empresa SinkSul, a busca por novos desafios o fez resgatar o sonho de abrir seu próprio negócio. Este sonho vinha desde o período de graduação e passou a ser o grande desafio de sua trajetória profissional e de sua vida.

"O sonho de montar uma empresa vinha de berço, meu pai sempre fabricou móveis e cresci no meio das máquinas. Na graduação, em um trabalho de empreendedorismo, levantei os números, as informações do mercado, as necessidades da SinkSul e de outras empresas da região, além das opções para o investimento inicial e tracei um plano de negócios, surgindo à busca por algo mais concreto".

"Percebi que os clientes desta área querem ver algo tangível, ou seja, uma estrutura confiável, com exemplos de trabalhos, com máquinas de alta tecnologia, foi o que sempre procurei quando contratei este tipo de trabalho. Para uma escolha na área de projetos, teria a comodidade do baixo investimento, no entanto precisaria de uma marca confiável, o que não tinha naquele momento".

Percebendo que a região não possuía empresa na área de Usinagem de Metais, Gabriel identificou e listou os possíveis clientes para o seu novo negócio, tendo identificado em torno de 16 possíveis empresas como clientes em potencial, isso somente na região sudoeste do Paraná, além da SinkSul que enviava suas peças para as cidades de Joinville e Jaraguá do Sul.

A empresa SinkSul, ao longo destes 14 anos, havia the proporcionado essa experiência, podendo, ainda, ser um de seus principais clientes. "Como projetista, observei que além da empresa em que trabalho, outras também buscavam soluções nesta área e para isso enviavam peças e projetos para outros locais muitas vezes distantes". A ideia de Gabriel era montar um negócio voltado para a área de projetos 
e então convidou um amigo, que mais tarde por falta de dinheiro "caiu fora", deixando-o ainda mais empolgado, pois se sentiu desafiado.

O sonho estava falando cada vez mais alto e Gabriel foi buscar empréstimos para seus investimentos iniciais, sendo que o centro de usinagem que seria o seu maior investimento custou $150.000,00$ dólares, fora os investimentos menores que eram necessários para que a empresa pudesse começar a trabalhar. Conseguiu o aluguel de um barracão com a prefeitura da cidade e em agosto de 2011 realizou seu sonho, abrindo seu negócio, iniciando assim, um novo ciclo em sua vida profissional. Agora ia ser seu próprio chefe e o melhor era poder continuar tendo a empresa que Ihe proporcionou oportunidades em sua carreira como sua principal parceira.

"A empresa em que trabalho neste momento possibilitaria a execução de trabalhos, o que asseguraria um mínimo de sobrevivência na fase inicial, teria que conseguir mais clientes, porém começava a ver um novo horizonte surgindo. As mudanças internas a fim de evitar o conflito de interesses foram imprescindíveis. Já no primeiro momento, outra pessoa foi direcionada para a cotação dos orçamentos e passei a não mais decidir que empresa executaria meus projetos. Procurei sempre deixar claro a todos os meus objetivos".

Desde o início de seu negócio em 2011, Gabriel conseguiu fechar os principais trabalhos com a SinkSul e também conquistou novos clientes ao longo destes 3 anos, visitando as empresas que havia listado como clientes potenciais e desenvolvendo projetos novos e diferentes dos que estava habituado. "Tivemos que desenvolver projetos completamente diferentes para outras empresas a fim de aplicar conhecimentos similares e utilizar ao máximo os equipamentos adquiridos".

Gabriel sabe que tem muito a ganhar permanecendo na SinkSul, pois tem uma brilhante carreira, um bom salário, uma segurança profissional, oportunidade de se aprimorar e se desenvolver devido às viagens e os cursos que a empresa lhe proporciona. Mas ao mesmo tempo, ele consegue visualizar uma grande oportunidade com sua empresa, realizando o seu grande sonho. Ele está ciente de que passará por dificuldades, mas terá a oportunidade de se tornar um empresário de sucesso, colocando suas ideias em práticas e galgando seus próprios passos rumo a uma nova etapa de sua vida profissional. 
Ao longo desses dois anos, Gabriel se desdobrou entre os trabalhos na SinkSul e em seu próprio negócio. Sua carga horária de trabalho diário é em torno de 16 horas, seis dias por semana, não conseguindo dedicar-se a sua vida pessoal. Em consequência, sua família tem cobrado mais sua presença e, além disso, neste ano, sua esposa voltou a estudar, ficando em outra cidade três dias da semana. Assim, é necessária dedicação total de Gabriel à sua filha nesses dias. "Entendo que se trata de um período, por isso todo este esforço e mais importante que a dedicação no trabalho é a compreensão e apoio da família".

Gabriel sente que é hora de buscar novos clientes e se dedicar para desenvolver seu negócio, para que possa ter sua estabilidade financeira. Com essa falta de tempo, ele não pode buscar novos clientes, pois não teria como executar os trabalhos. Além disso, outras empresas da região que ficaram sabendo da sua empresa o procuraram, mas Gabriel não tem como atendê-los. Hoje, o melhor cliente da empresa de Gabriel é a SinkSul, que representa $70 \%$ do seu faturamento e sua preocupação é que com seu desligamento, a empresa resolva não fechar novos negócios.

"Por fim, aprendi que se faz necessário equilibrar o trabalho, família e a fé. Aprendi que preciso de um novo desafio a cada dia e estes precisam me meter medo de verdade. E que sempre temos escolhas a fazer, porém temos apenas uma opção fazer dar certo e frente a isso é preciso fazer a melhor escolha."

\section{A decisão}

Gabriel sabe que sua empresa tem potencial, mas a estabilidade financeira que possui hoje é um fator que o preocupa. Diante disso, o que Gabriel deve fazer? Continuar na SinkSul e vender seu negócio, permitindo assim ter seu sonho realizado por outra pessoa? Ou acreditar em todo seu potencial e encarar o desafio dedicando-se de maneira integral ao seu sonho? 


\section{NOTAS DE ENSINO}

\section{Objetivos educacionais}

A partir das análises da trajetória profissional e pessoal de Gabriel, o caso tem como objetivo que os alunos vivenciem a importância da decisão que precisa ser tomada e se coloquem no lugar de Gabriel, analisando as vantagens e desvantagens de cada uma das alternativas. Também que possam desenvolver a importância de analisar os seguintes objetivos de ensino:

(1) Abordar os conceitos de empreendedorismo e fazer com que os alunos discutam o papel do empreendedor para o mercado e sociedade;

(2) Abordar as etapas e a importância do Plano de Negócios para analisar a viabilidade, para que os alunos compreendam a importância de se construir uma base sólida no planejamento e no desenvolvimento do seu negócio, propiciando assim a sustentabilidade do empreendimento;

(3) Abordar as características empreendedoras para que os alunos identifiquem a importância do empreendedor cuidar de seu desenvolvimento pessoal para o sucesso dos seus negócios.

\section{Utilização recomendada}

O caso foi elaborado para utilização em cursos de graduação em administração e marketing, além de cursos de tecnologia em gestão de negócios e gestão empresarial que abordem os conceitos de empreendedorismo, plano de negócios, características empreendedoras, estando associado aos conteúdos de estratégia, marketing, liderança, planejamento de carreira.

\section{Obtenção dos dados}

As informações foram obtidas através de entrevista concedida por Gabriel. Os nomes da empresa e do personagem são fictícios para preservar suas identidades. 


\section{Situação-problema}

Gabriel tem à sua frente uma importante decisão para tomar, seguir seu sonho e trilhar seu caminho ou permanecer na empresa que trouxe oportunidades na carreira?

Esta é a questão central do caso. Para tanto, recomenda-se que discussões sejam feitas com base nas teorias sugeridas sobre: empreendedorismo, plano de negócios e características empreendedoras.

\section{Sugestão de questões para discussão}

1) O futuro empreendedor precisa conhecer a realidade do seu negócio e do seu mercado, que é possível ser realizado através do plano de negócios. Desta forma, quais os principais passos a serem realizados em um plano de negócios? Dentro deste contexto, quais etapas você observa que foram realizadas por Gabriel e quais não foram abordadas ou precisam ser aprofundadas?

2) Gabriel possui algumas características empreendedoras, descreva as que foram identificadas e sua importância para o negócio. Se houverem características que ele necessite desenvolver, sugira ações para o seu desenvolvimento.

3) Considerando as características empreendedoras, você tomaria a decisão de desligar-se do seu emprego atual e dar continuidade ao seu negócio? Utilizando-se destas características de Gabriel, elabore uma proposta para manter a SinkSul como cliente.

4) A trajetória profissional e acadêmica de Gabriel the proporcionaram conhecimentos técnico e administrativo necessários para gerir um negócio próprio? Que relação a trajetória profissional de Gabriel tem com os conceitos de empreendedorismo? 
Análise do caso

\section{Questão 1}

O futuro empreendedor precisa conhecer a realidade do seu negócio e do seu mercado, que é possível ser realizado através do plano de negócios, desta forma quais os principais passos a serem realizados em um plano de negócios? Dentro desse contexto, quais etapas você observa que foram realizadas por Gabriel e quais não foram abordadas ou precisam ser aprofundadas?

As informações para o plano de negócios foram identificadas e mapeadas por Gabriel por meio do conhecimento adquirido da SinkSul, suas necessidades enquanto colaborador/comprador da SinkSul, entrevistas com empresas da região e o crescimento do mercado de usinagem. Conforme o portal Usinagem-Tech (2013), em 2011, o Brasil era o 9 colocado em consumo de ferramentas de corte em metal duro, sem contar outras oportunidades oferecidas pelo setor como, por exemplo, a fabricação de veículos e a ampliação das montadoras no Brasil. Outros aspectos observados por Gabriel estavam relacionados a sua viabilidade financeira, seu planejamento para aquisição de máquinas e equipamentos, local para execução de seus trabalhos, além de sua preocupação com os investimentos inicias, fornecendo giro através dos trabalhos realizados para a SinkSul.

O Plano de Negócios é de suma importância para um novo empreendimento, tanto que possui o apoio de entidades fortes para assessorar o futuro empreendedor, como é o caso do SEBRAE-PR (2013), onde descreve que o "plano de negócios é uma metodologia de planejamento e ordenação de cada um de seus sonhos e ideias visando torná-los realidade de uma maneira rentável."

Dolabela (1999) trouxe o Plano de Negócios como uma linguagem, onde é possível identificar os detalhes do empreendimento, como produtos ou serviços, clientes, aspectos tecnológicos de produção, formas de vendas e distribuição, todos os aspectos financeiros como custos, lucros, etc., além da preocupação com as questões legais. Todo este processo precisa estar fundamentado na garantia de viabilidade e sobrevivência do negócio. 
Para Dornelas (2001), é importante que o empreendedor tenha a preocupação em seu plano de negócios e procure ser o mais realista possível nos levantamentos realizados, evitando a perda de todo o investimento realizado incialmente.

Hisrich, Peters e Shepherd (2009) identificaram o Plano de Negócios como uma etapa importante no processo de empreender (figura 1).

$\mathrm{Na}$ visão de Hashimoto et al. (2012), o Plano de Negócios ganhou maior destaque atualmente com as empresas relacionadas à internet e startups, tendo seu conceito ainda mais disseminado e conhecido pelos empreendedores. Este plano é de suma importância por trazer detalhes do negócio, seus objetivos, clientela a ser atendida, além da viabilidade do negócio, obtenção de recursos e parcerias importantes.

A dinâmica dos negócios mostra que com os novos modelos de negócios e os crescimentos dos pequenos empreendimentos ao longo dos últimos anos, no período de 2008 a 2013, foram mais de três milhões de empreendedores registrados, conforme informação do Portal do Empreendedor (2013). Estes números apenas reforçam o quanto o plano é importante para a criação de um negócio sustentável. 
-Avalição da oportunidade;

- Criação e dimensão da oportunidade

- Valor real e percebido da oportunidade;

Identificare

avaliar

oportunidade

- Riscos e retorno da oportunidade;

- oportunidade versus habilidades e metas pessoais;

-Ambiente competitivo.

\section{-Sumário}

- Resumo executivo;

- Descrição do negócio e do setor;

Desenvolver

Plano de

negócios

-Planos (tecnológico, marketing, financeiro, produção.

organizacional, operacional;

-Resumos;

-Apendices.

- Recursos pessoais, de amigos ou família;

- Angels eCapitalistais de risco;

Determinar e

- Bancos (empréstimos, financiamentos);

captar recursos

- Governo;

necessários

-incubadoras

FIGURA 1 - Processo de empreender

Fonte: Adaptado de Hisrich, Peters e Shepherd (2009).

Quando se analisa as etapas do processo de empreender definidas por Hisrich, Peters e Shepherd (2009) e o empreendimento de Gabriel, observa-se que todas as etapas foram cumpridas, demonstrando sua afinidade com o negócio desenvolvido. 


\begin{tabular}{|c|c|}
\hline $\begin{array}{c}\text { PROCESSO DE } \\
\text { EMPREENDER }\end{array}$ & PROCESSO DESENVOLVIDO POR GABRIEL \\
\hline Identificar e avaliar oportunidade & $\begin{array}{c}\text { Busca de conhecimento na área de atuação, através da } \\
\text { empresa SinkSul; } \\
\text { Identificação das necessidades de mercado; } \\
\text { Abertura de seu negócio; } \\
\text { Desenvolvimento de clientes; } \\
\text { Atuação em seu negócio. }\end{array}$ \\
\hline Desenvolver Plano de negócios & $\begin{array}{c}\text { Gabriel conhece profundamente o negócio, porém há a } \\
\text { necessidade de montar seu planejamento para sua } \\
\text { continuidade e expansão, inclusive pensando na } \\
\text { possibilidade de perda de seu principal cliente. }\end{array}$ \\
\hline Determinar e captar recursos & $\begin{array}{c}\text { Gabriel soube realizar de forma eficaz seu planejamento } \\
\text { necessários } \\
\text { não seu certo e posteriormente, empréstimo bancário e } \\
\text { parcerias para iniciar seus primeiros investimentos. }\end{array}$ \\
\hline Gerenciar a empresa criada & $\begin{array}{c}\text { Atualmente administra seu negócio de forma eficaz e } \\
\text { conhece os fatores críticos para o seu crescimento e } \\
\text { estes estão relacionados ao processo de tomada de } \\
\text { decisão. }\end{array}$ \\
\hline
\end{tabular}

QUADRO 1 - Processo de Empreender Desenvolvido por Gabriel

Fonte: adaptado de Hisrich, Peters e Shepherd (2009).

\section{Questão 2}

Gabriel possui algumas características empreendedoras, descreva as que foram identificadas e sua importância para o negócio. Se houver características que ele necessite desenvolver, sugira ações para o seu desenvolvimento.

Elaborar o Plano de Negócios é de suma importância. Porém, Gabriel também precisa possuir algumas características pessoais para dar continuidade a esse negócio, caso contrário, na primeira dificuldade irá desistir. Dornelas (2001) definiu algumas características que reforçam esta importância: 


\begin{tabular}{|c|c|c|}
\hline \multicolumn{3}{|c|}{$\begin{array}{l}\text { REVITA } \\
\text { Revista de Empreandedorismo } \\
\text { e Geståo de Pequenas Empresas }\end{array}$} \\
\hline CARACTERISTICA & COMPORTAMENTO APRESENTADO & COMPORTAMENTO GABRIEL \\
\hline São visionários & $\begin{array}{l}\text { Possuem visão de como será o futuro para } \\
\text { seu negócio e sua vida, e tem a habilidade } \\
\text { de implementar seus sonhos. }\end{array}$ & $\begin{array}{l}\text { Busca por novos desafios o fez } \\
\text { resgatar seu sonho desde a } \\
\text { graduação. }\end{array}$ \\
\hline $\begin{array}{l}\text { Sabem tomar } \\
\text { decisões }\end{array}$ & $\begin{array}{c}\text { Não se sentem inseguros e sabem tomar } \\
\text { as decisões na hora certa. }\end{array}$ & $\begin{array}{l}\text { Abertura de sua empresa em } \\
2011 .\end{array}$ \\
\hline $\begin{array}{l}\text { São indivíduos que } \\
\text { fazem a diferença }\end{array}$ & $\begin{array}{l}\text { Transformam algo de difícil definição, em } \\
\text { algo que funciona, transformando o que é } \\
\text { possível em realidade. }\end{array}$ & $\begin{array}{l}\text { Realizou seu sonho, abriu sua } \\
\text { empresa e acredita nos } \\
\text { conhecimentos que adquiriu. }\end{array}$ \\
\hline $\begin{array}{l}\text { Sabem explorar ao } \\
\text { máximo as } \\
\text { oportunidades }\end{array}$ & $\begin{array}{l}\text { Para os visionários as boas ideias estão } \\
\text { em algo que todos conseguem ver, mas } \\
\text { não identificam algo prático para } \\
\text { transformá-las em oportunidades. }\end{array}$ & $\begin{array}{l}\text { Ideias inovadoras e projetos } \\
\text { diferenciados para otimização de } \\
\text { seus recursos. }\end{array}$ \\
\hline $\begin{array}{l}\text { São determinados } \\
\text { e dinâmicos }\end{array}$ & $\begin{array}{l}\text { Eles implementam suas ações em total } \\
\text { comprometimento, atropelam as } \\
\text { adversidades, ultrapassando os obstáculos } \\
\text { com uma vontade enorme de fazer as } \\
\text { coisas acontecerem. }\end{array}$ & $\begin{array}{l}\text { Esforço para desdobrar-se entre } \\
\text { a SinkSul e sua empresa, } \\
\text { deixando sua vida pessoal. }\end{array}$ \\
\hline São dedicados & $\begin{array}{l}\text { Eles se dedicam } 24 \text { horas por dia, } 7 \text { dias } \\
\text { por semana ao seu empreendimento. }\end{array}$ & $\begin{array}{l}\text { Procura, mesmo se desdobrando, } \\
\text { dar atenção ao seu negócio. }\end{array}$ \\
\hline $\begin{array}{l}\text { São otimistas e } \\
\text { apaixonados pelo } \\
\text { que fazem }\end{array}$ & $\begin{array}{l}\text { Eles adoram o trabalho que realizam e é } \\
\text { esse amor que os mantêm cada dia mais } \\
\text { animados e autodeterminados. }\end{array}$ & $\begin{array}{c}\text { Gabriel é apaixonado por sua } \\
\text { área de atuação, dando } \\
\text { continuidade a sua carreira em } \\
\text { seu próprio negócio. }\end{array}$ \\
\hline $\begin{array}{l}\text { São independentes } \\
\text { e constroem o } \\
\text { próprio destino }\end{array}$ & $\begin{array}{l}\text { Eles querem ser independentes em vez de } \\
\text { empregados e estão sempre à frente das } \\
\text { mudanças. }\end{array}$ & $\begin{array}{c}\text { Sabe que é o momento de buscar } \\
\text { novos clientes e ampliar seu } \\
\text { negócio. }\end{array}$ \\
\hline Ficam ricos & $\begin{array}{l}\text { Esse não é o principal objetivo dos } \\
\text { empreendedores, acreditam que o dinheiro } \\
\text { é a consequência do seu trabalho. }\end{array}$ & $\begin{array}{l}\text { O mais importante é a dedicação } \\
\text { ao trabalho e o apoio da família. }\end{array}$ \\
\hline $\begin{array}{c}\text { São líderes e } \\
\text { formadores de } \\
\text { equipe }\end{array}$ & $\begin{array}{l}\text { Os empreendedores são respeitados e } \\
\text { adorados por seus funcionários, e tem um } \\
\text { senso de liderança incomum. }\end{array}$ & $\begin{array}{l}\text { Ao longo dos } 14 \text { anos conquistou } \\
\text { posições e responsabilidades } \\
\text { importantes na SinkSul. }\end{array}$ \\
\hline $\begin{array}{l}\text { São bem } \\
\text { relacionados }\end{array}$ & $\begin{array}{l}\text { Possuem uma rede de contatos que os } \\
\text { auxiliam no ambiente externo. }\end{array}$ & $\begin{array}{l}\text { Contatos com empresas da } \\
\text { região, prefeitura, bancos, } \\
\text { contatos que apoiaram seus } \\
\text { investimentos iniciais. } \\
\end{array}$ \\
\hline São organizados & $\begin{array}{c}\text { Sabem obter e alocar os recursos } \\
\text { materiais, humanos, tecnológicos e } \\
\text { financeiros de forma racional procurando o } \\
\text { melhor desempenho para o negócio. }\end{array}$ & $\begin{array}{c}\text { Procura otimizar seus recursos } \\
\text { disponíveis. }\end{array}$ \\
\hline $\begin{array}{c}\text { Planejam, } \\
\text { planejam, planejam }\end{array}$ & $\begin{array}{c}\text { Os empreendedores de sucesso planejam } \\
\text { cada passo do seu negócio. }\end{array}$ & $\begin{array}{c}\text { Busca por novos clientes para } \\
\text { desligar-se de seu emprego atual. }\end{array}$ \\
\hline $\begin{array}{c}\text { Possuem } \\
\text { conhecimento }\end{array}$ & $\begin{array}{l}\text { São sedentos pelo saber e aprendem } \\
\text { continuamente. }\end{array}$ & $\begin{array}{l}\text { Participa de feiras e eventos de } \\
\text { sua área para manter-se } \\
\text { atualizado e na busca de novas } \\
\text { ideias e tecnologias. } \\
\end{array}$ \\
\hline $\begin{array}{l}\text { Assumem riscos } \\
\text { calculados }\end{array}$ & Assume riscos e sabe gerenciar esse risco. & $\begin{array}{l}\text { Tem ciência que ao deixar a } \\
\text { SinkSul pode perder um de seus } \\
\text { maiores clientes. }\end{array}$ \\
\hline $\begin{array}{l}\text { Criam valor para a } \\
\text { sociedade }\end{array}$ & $\begin{array}{l}\text { Utilizam seu conhecimento para criar valor } \\
\text { para a sociedade. }\end{array}$ & $\begin{array}{c}\text { Procurou legalizar seu negócio e } \\
\text { seus planos futuros são ampliar e } \\
\text { poder contar com outros } \\
\text { funcionários. }\end{array}$ \\
\hline
\end{tabular}

QUADRO 2 - Características dos Empreendedores de Sucesso

Fonte: adaptado de Dornelas (2001).

BACCIN, S. S.; PEREIRA, C. M. D.; MARINHO, S. V.; ALBERTON, A. Empreender ou permanecer em uma grande empresa: sonho ou estabilidade? Revista de

Empreendedorismo e Gestão de Pequenas Empresas, v. 4, n. 1, 2015. 
O empreendedor, segundo Dornelas (2001), é aquele que tem a visão de um novo produto ou serviço que satisfaça as necessidades dos clientes, que faz as coisas acontecerem antes que qualquer outra pessoa. Ou seja, que se antecipa, criando vantagem perante os outros.

Estudos mostram que as características mais marcantes apresentadas pelos empreendedores estão baseadas na inovação, liderança, independência, criatividade, riscos moderados, originalidade, otimismo, sensibilidade, autoconfiança, tendência a confiar nas pessoas, entre outras. (CAMARA; ANDALÉCIO, 2012).

Ainda para Dornelas:

[...] Os empreendedores são pessoas diferenciadas, que possuem motivação singular, apaixonadas pelo que fazem, não se contentam em ser mais um na multidão, querem ser reconhecidas e admiradas, referenciadas e imitadas, querem deixar um legado. Uma vez que os empreendedores estão mudando o mundo, seu comportamento e o próprio processo empreendedor devem ser estudados e entendidos (DORNELAS, 2001, p. 19).

Ao estudar o empreendedor sob a ótica comportamental, McClelland (1971) afirma que a motivação maior na decisão de empreender é a alta necessidade de realização. O autor afirma que as pessoas que possuem forte desejo de realização, tendem a assumir riscos e preferem depender da própria habilidade para chegar ao sucesso. Shapero e Sokol (1982) afirmam que a decisão de empreender envolve diversos fatores, como a influência de familiares, amigos e a projeção de carreira. Esses fatores foram observados no caso de Gabriel.

Já segundo Kirzner (1973 apud DORNELAS, 2001, p. 37) "o empreendedor é aquele que cria um equilíbrio, encontrando uma posição clara e positiva em um ambiente de caos e turbulência, ou seja, identifica oportunidades na ordem presente".

O GEM (Global Entrepreneurship Monitor, 2012) realizou uma pesquisa sobre o perfil empreendedor, onde se pode identificar que a escolha a ser tomada possui plenas condições de ser bem sucedida, pois:

[...] Quando indivíduos são capazes de reconhecer as oportunidades de negócios no ambiente em que atuam e de perceber que possuem capacidade para explorá-las, toda a sociedade é beneficiada, seja com o 
aumento da criação de ocupações, seja com o aumento da riqueza do país e sua distribuição (GEM 2012, p. 8).

As características desenvolvidas por Gabriel ao longo de sua carreira e no desenvolvimento de seu negócio traduzem sua capacidade de realização e adaptação ao mercado, identificando oportunidades e agregando valor, tanto aos trabalhos desenvolvidos para a SinkSul quanto para seu próprio empreendimento, demonstrando seu profissionalismo e visão do negócio.

\section{Questão 3}

Considerando as características empreendedoras, você tomaria a decisão de desligar-se do seu emprego atual e dar continuidade ao seu negócio? Utilizandose destas características de Gabriel, elabore uma proposta para manter a SinkSul como cliente.

A negociação faz parte do dia a dia do empreendedor. Para a sustentabilidade do seu negócio é importante que saiba negociar com seus clientes, fornecedores e parceiros, para melhor realizar suas compras, suas entregas, buscando assim, oferecer os melhores produtos e serviços.

Pode-se observar que a negociação está presente nas características empreendedoras descritas por Dornelas (2009), através de networks, definidos como bem relacionados, formadores de equipes, quando assumem riscos e criam valor na sociedade, estando presente nas diversas características do empreendedor.

Hisrich, Peters e Shepherd (2009) elucidam que o modo de agir dos empreendedores é uma ação intencional e estas intenções influenciam em suas motivações. Esta força é que faz com que o desejo de realizar seja mais forte, pois acreditam que o sonho pode dar certo. Estas motivações foram definidas pelos autores como intenções empreendedoras e acrescentadas da autoeficácia, que está relacionada à iniciativa e a persistência, melhorando o desempenho e fazendo com que o empreendedor realize um esforço maior para realizar seus objetivos. Este é um ponto bastante importante que foi identificado nas características de Gabriel.

Sabe-se que Gabriel tem muito a ganhar permanecendo na SinkSul, pois tem uma brilhante carreira, um bom salário, uma segurança profissional, 
oportunidade de se aprimorar e se desenvolver devido às viagens e os cursos que a empresa lhe proporciona. Mas ao mesmo tempo, ele consegue visualizar uma grande oportunidade com sua empresa, realizando o seu grande sonho, sabendo que passará por dificuldades, mas tendo a oportunidade de se tornar um empresário de sucesso, colocando suas ideias em práticas e galgando seus próprios passos rumo a uma nova etapa de sua vida profissional.

Hisrich, Peters e Shepherd (2009) identificam este processo de predisposição percebida, onde a indecisão de Gabriel está relacionada diretamente ao processo de tomadas de decisão frente às vantagens e desvantagens, tendo a necessidade de gerar recompensas pessoais que estejam de acordo com o desejo do empreendedor. Neste sentido, pode-se observar que Gabriel ainda possui insegurança, pois teme perder seu principal cliente. Os autores definem a rede de apoio profissional, onde empresas atuam como mentoras deste novo empreendimento, o que poderia ser uma proposta interessante para Gabriel fazer para a empresa SinkSul, já que esta também possui interesse nos conhecimentos de Gabriel.

\section{Questão 4}

A trajetória profissional e acadêmica de Gabriel lhe proporcionaram conhecimentos técnico e administrativo necessários para gerir um negócio próprio? Que relação a trajetória profissional de Gabriel tem com os conceitos de empreendedorismo?

O conhecimento tornou-se um ativo fundamental para as organizações, especialmente quando falamos em setores que necessitam de inovações constantes, como o setor escolhido por Gabriel. Porém, para que as informações sejam transformadas em conhecimento existe um longo caminho. Nonaka e Takeuchi (1997) definem estes conhecimentos como tácito, relacionado à aplicação prática, e o explícito, voltado à mente, aos aspectos teóricos e técnicos. A interação desses conhecimentos desencadeia um processo de mobilidade, gerando novos conhecimento e, consequentemente, estando associado também a inovação. 
Shook, Priem e Macgee, (2003) traz alguns aspectos importantes relacionados ao empreendedor individual, suas características pessoais como cultura, experiências pessoais e profissionais, escolaridade, além de conhecimentos adquiridos. Certamente, essas informações contribuem para o processo de tomadas de decisão apresentados na figura 2.

Pelo que se pode perceber no caso de Gabriel, ele possui conhecimento técnico sobre o seu negócio, isso pode ser identificado pelo seu curso técnico no CEFET, pela sua pós-graduação em engenharia de produção na UTFPR e também pela sua experiência dentro da SinkSul. Já quando cita o conhecimento administrativo, deve-se considerar que apenas a sua faculdade em administração não garante que ele tenha o conhecimento necessário nas diversas áreas que serão necessárias, como vendas, finanças, marketing, etc.

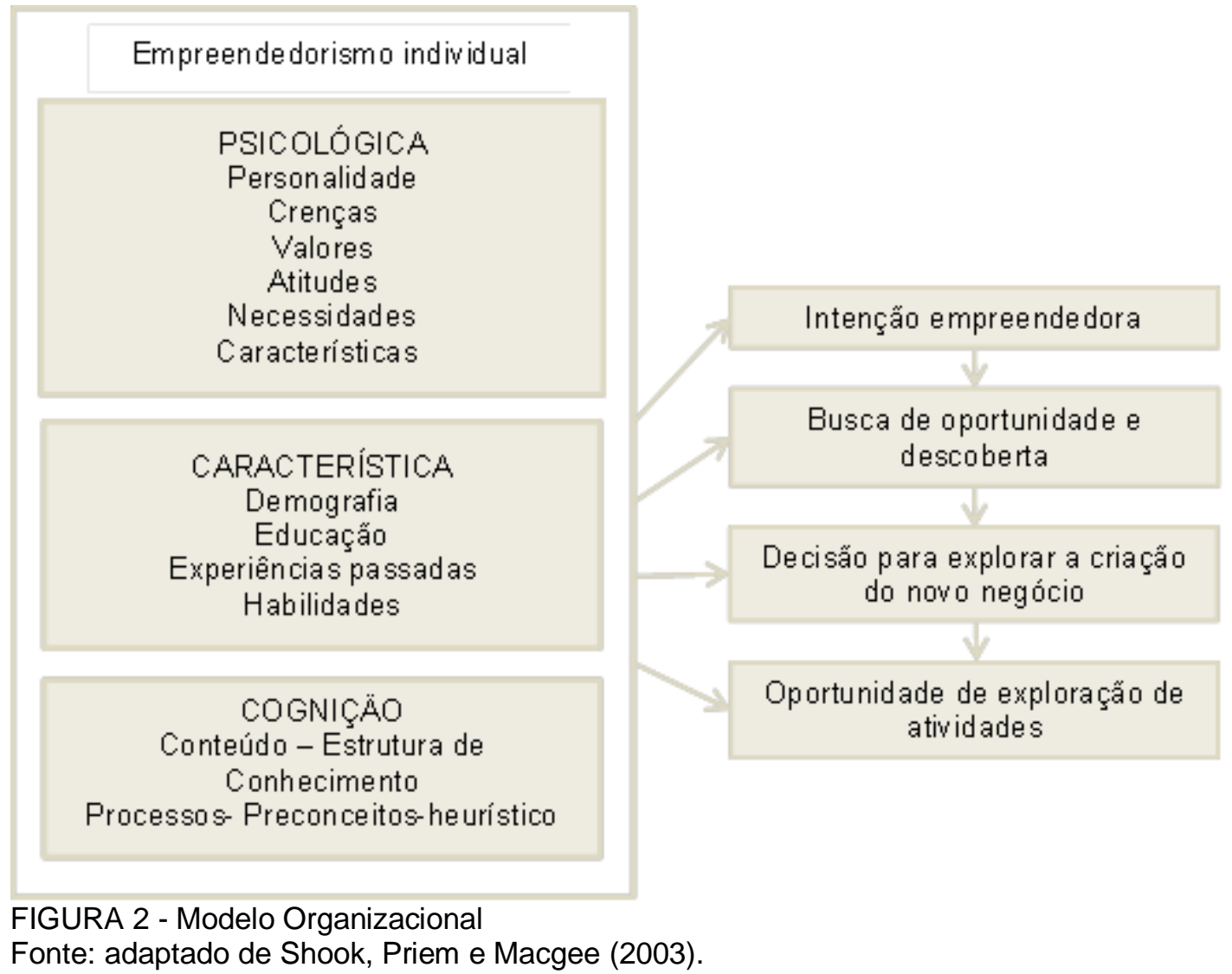

Gabriel ainda assim pode dar continuidade ao seu negócio, pois os clientes que normalmente atuam nesses seguimentos acabam exigindo conhecimentos mais

BACCIN, S. S.; PEREIRA, C. M. D.; MARINHO, S. V.; ALBERTON, A. Empreender ou permanecer em uma grande empresa: sonho ou estabilidade? Revista de 
aprofundados no nível técnico. Para dar continuidade ao seu negócio ele possui conhecimentos voltados à área administrativa, mesmo que em uma proporção menor. Isso pode ser observado pelo fato dele atuar ao longo de dois anos, o que mostra os conhecimentos necessários para o momento atual da empresa. Futuramente, Gabriel deve pensar em investimentos que ampliem seu negócio e possam lhe dar ainda mais visibilidade, proporcionando crescimento duradouro.

\section{A decisão de Gabriel}

Não existem respostas certas e alguns aspectos devem ser considerados. Tomando a decisão de ficar na empresa irá realizar-se profissionalmente e desfazer o sentimento de não ser mais produtivo? Sair lhe garantirá sucesso profissional e pessoal?

\section{Referências:}

CAMARA, E. C; ANDALÉCIO, A. M. L. Características empreendedoras: um estudo de caso com farmacêuticos utilizando o modelo de McClelland. Revista de Empreendedorismo e Gestão de Pequenas Empresas, v. 1, n.3, 2012.

DOLABELA, F. Oficina do Empreendedor. 6 ed. São Paulo: Cultura, 1999.

DORNELAS, J. C. A. Empreendedorismo: Transformando Idéias em Negócios. 2ed. Rio de Janeiro: Campus, 2001.

GEM. Global Entrepreneurship Monitor. Empreendedorismo no Brasil - Relatório Executivo. 2012.

HASHIMOTO, M.; LOPES, R. M.; ANDREASSI, T. NASSIFE. V. M. J. Práticas de empreendedorismo: casos e planos de negócios. Livro eletrônico. Elsevier, 2012. Acesso em 09 set. 2013.

HISRICH, R. D.; PETERS, M. P.; SHEPHERD, D. A. Empreendedorismo. 7ํㅡㄹ Ed. Porto Alegre: Bookman, 2009.

MCCLELLAND, D. C. The achievement motive in economic growth. In: KILBY, P. (Ed.) Entrepreneurship and economic development. New York: The Free Press, 1971. p.109-122.

BACCIN, S. S.; PEREIRA, C. M. D.; MARINHO, S. V.; ALBERTON, A. Empreender ou permanecer em uma grande empresa: sonho ou estabilidade? Revista de 
NONAKA, I.; TAKEUCHI, H. Criação de conhecimento na empresa. Como as empresas japonesas geram a dinâmica da inovação. 4aed. Rio de Janeiro: Campus, 1997.

PORTAL DO EMPREENDEDOR. Rede Sim. Disponível em: <http://www.portaldoempreendedor.gov.br/>. Acesso em: 09 set. 2014.

Revista eletrônica Usinagem Tech. Disponível em: <http://usinagemtech.com.br/index.php/2011/11/21/qual-o-tamanho-do-mercado-brasileiro/>. Acesso em: 25 jul. 2014.

SEBRAE-PR. PORTAL DO EMPREENDEDOR Disponível em: <http://www.sebraepr.com.br/Portallnternet/Destaques/Quero-abrir-minhaempresa/Plano-de-Neg\%C3\%B3cios.>. Acesso em: 24 jul. 2014.

SHAPERO, A.; SOKOL, L. The Social Dimensions of Entrepreneurship. Encyclopedia of Entrepreneurship, p. 72-90, 1982.

SHOOK, C. L, PRIEM, R. L.; MCGEE, J. E. Venture creation and the enterprising individual: a review and synthesis. Journal of Management, v. 29, n. 3, p. 379-399, 2003. 